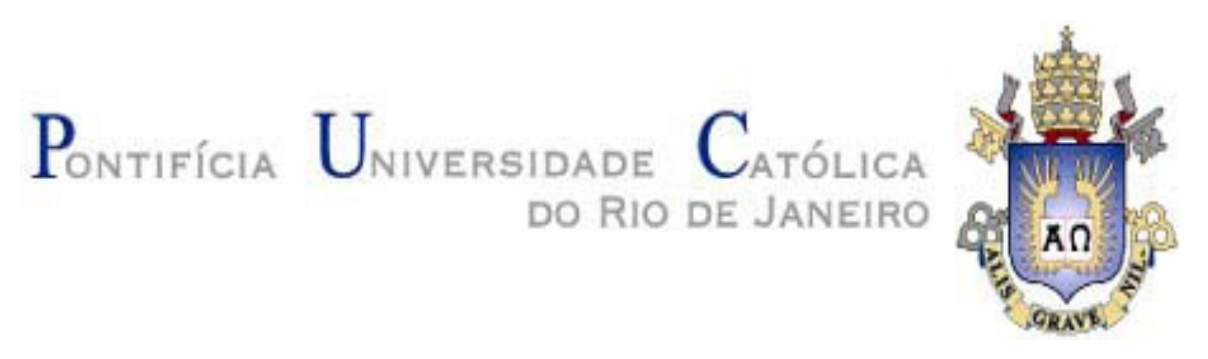

Marina Schuabb Salgado

\title{
Avaliação do Projeto de Construção da Linha 4 do Metrô de São Paulo pela Metodologia de Opções Reais
}

Dissertação de Mestrado

Dissertação apresentada ao Programa de Pósgraduação em Administração de Empresas da PUC-Rio como requisito parcial para obtenção do título de Mestre em Administração de Empresas.

Orientador: Prof. Luiz Eduardo Teixeira Brandão

Rio de Janeiro Junho de 2009 


\title{
Pontifícia Universidade Católica $_{\text {a }}$

\section{Marina Schuabb Salgado}

\section{Avaliação do Projeto de Construção da Linha 4 do Metrô de São Paulo pela Metodologia de Opções Reais}

\begin{abstract}
Dissertação apresentada como requisito parcial para obtenção do grau de Mestre pelo Programa de Pósgraduação em Administração de Empresas da PUC-Rio. Aprovada pela Comissão Examinadora abaixo assinada.
\end{abstract}

Prof. Luiz Eduardo Teixeira Brandão Orientador Departamento de Administração - PUC-Rio

Prof. Leonardo Lima Gomes Departamento de Administração - PUC-Rio

Prof. Eduardo Cesar Gomes Saraiva BNDES

Prof. Nizar Messari Vice-Decano de Pós-Graduação do CCS

Rio de Janeiro, 29 de junho de 2009 
Todos os direitos reservados. É proibida a reprodução total ou parcial do trabalho sem autorização da universidade, da autora e do orientador.

\section{Marina Schuabb Salgado}

Graduada em Ciências Econômicas na Universidade Federal do Rio de Janeiro em 2005, ingressando no Programa de Pós-Graduação em Administração da PUC-Rio em 2007.

Ficha Catalográfica

Salgado, Marina Schuabb

Avaliação do projeto de construção da linha 4 do metro de São Paulo pela metodologia de opções reais / Marina Schuabb Salgado ; orientador: Luiz Eduardo Teixeira Brandão. - 2009. 69f. : il. (color.) ; $30 \mathrm{~cm}$

Dissertação (Mestrado em Administração)Pontifícia Universidade Católica do Rio de Janeiro, Rio de Janeiro, 2009.

Inclui bibliografia

1. Administração - Teses. 2. Parceria públicoprivada. 3. Avaliação de projetos. 4. Opções reais. 5. Método de avaliação tradicional. I. Brandão, Luiz Eduardo Teixeira. II. Pontifícia Universidade Católica do Rio de Janeiro. Departamento de Administração. III. Título. 


\section{Resumo}

Salgado, Marina Schuabb; Brandão, Luiz Eduardo Teixeira. Avaliação do Projeto de Construção da Linha 4 do Metrô de São Paulo pela Metodologia de Opções Reais. Rio de Janeiro, 2009. 69p. Dissertação de Mestrado Departamento de Administração, Pontifícia Universidade Católica do Rio de Janeiro

Devido à escassez de recursos públicos nas últimas décadas, as Parcerias Público-Privadas têm sido cada vez mais utilizadas pelos governos como alternativa a investimentos de infra-estrutura de grande porte. O setor de transporte abriga excelentes oportunidades para a aplicação de tal parceria, e a correta avaliação deste tipo de projeto é de grande interesse da sociedade como um todo. A Metodologia Tradicional avalia as Parcerias Público-Privadas desconsiderando as flexibilidades deste tipo de projeto. Nesta dissertação, propõe-se a avaliação por Opções Reais, como complementação a forma tradicional de análise, introduzindo risco, incertezas e flexibilidades ao modelo clássico, como a incerteza de tráfego e garantias contratuais. Este modelo é aplicado ao Edital de Concorrência Internacional n ${ }^{\circ}$. 42325212, referente à concessão patrocinada para a exploração e operação da Linha 4 do Metrô de São Paulo e compara-se a avaliação pelo método de Avaliação Tradicional com o método das Opções Reais. Os resultados indicam que a Metodologia Tradicional não consegue incorporar as flexibilidades do projeto, enquanto que, a Teoria das Opções Reais os incorpora, mostrando-se mais adequada para a avaliação de tal projeto.

\section{Palavras-chave}

Parceria público-privada; avaliação de projetos; opções reais; método de avaliação tradicional. 


\section{Abstract}

Salgado, Marina Schuabb; Brandão, Luiz Eduardo Teixeira (Advisor). A Real Option Analysis of the Line 4 Subway Construction Project in São Paulo. Rio de Janeiro, 2009. 69p. MSc. Dissertation - Departamento de Administração, Pontifícia Universidade Católica do Rio de Janeiro

Due to a lack of public funding in the last decade for infrastructure projects, private capital has been encouraged by government to participate in Public Private Partnerships (PPP). Transportation sector is a good example of opportunities to such association. The correct valuation of those types of projects is in the best interest of all society, but Traditional Methods, such as discounted cash flows, do not capture the value of the flexibilities embedded in those projects. This work proposes the use of Real Options Method as a complement to Traditional Analysis, by considering risks and uncertainties and flexibilities. The model was applied to the International Public Bid $n^{\circ} 42325212$, which relates to the construction and operation of Line 4 of São Paulo City subway. By comparing both methods, traditional and real options, this work seeks to provide best way to measure this kind of project risks. The results suggest that Traditional Method does not considerate projects flexibilities, meanwhile, Real Optional Analysis does, and signalizing that is method is more suitable for this kind of project analysis.

\section{Keywords}

Public private partnerships; project valuation; real options analysis; traditional analysis. 


\section{Sumário}

1. Introdução 11

2. Revisão de Literatura 13

3. As Parcerias Público-Privadas (PPPS) 16

4. Modelo Teórico 20

4.1. Avaliação Tradicional 20

4.2. Opções Financeiras 23

4.3. Método das Opções Reais 25

5. O Projeto de Construção da Linha 4 do Metrô de São Paulo 28

5.1. Histórico 28

5.2. O Projeto 28

5.2.1. Fase I 29

5.2.2. Fase II 30

5.2.3. Projeção de Demanda 31

5.2.4. As Receitas 31

5.2.4.1. Receitas Tarifárias 31

5.2.4.1.1. Contraprestação Pecuniária 34

5.2.4.2. Receitas Não Tarifárias 35

5.2.5. Riscos 35 
5.2.5.1. Risco de Câmbio 35

5.2.5.2. Risco de Construção 35

5.2.5.3. Risco de Integração 36

5.2.5.4. Risco de Tráfego 36

5.2.6. Mitigação de Riscos 36

5.3. Avaliação pelo Fluxo de Caixa Descontado 39

5.3.1. Determinação do WACC 39

5.3.2. Determinação da Demanda 40

5.3.3. Determinação das Receitas $\quad 40$

5.3.4. Estimativa de Custos 41

5.3.5. Impostos 41

5.4. Determinação do Fluxo de Caixa Livre 41

6. Avaliação por Opções Reais 44

6.1. Determinação da Incerteza 44

6.2. Avaliação Neutra ao Risco 47

6.3. Faixas de Garantias Governamentais 48

6.4. Barreira Limite ao Tráfego 50

6.5. Cálculo do Valor Presente 51

6.6. Resultados 51

6.6.1. Valor do Projeto 52

6.6.2. Análise com Barreiras no Número de Passageiros 53

6.6.3. Análise do Projeto Considerando a Mitigação do Risco de Trafego 54

6.6.3.1. Com 10 Anos de Faixas de Mitigação de Risco 54

6.6.3.2. Com 20 Anos de Faixas de Mitigação de Risco 55

$\begin{array}{ll}\text { 7. Conclusões } & 57\end{array}$

8. Referências Bibliográficas $\quad 59$ 
9. Apêndices 64

9.1. Fluxo de Caixa Descontado com Contraprestação Pecuniária 64

9.2. Fluxo de Caixa Descontado sem Contraprestação Pecuniária 67 


\section{Lista de figuras}

Figura 1 - Mapa do projeto de construção do Metrô de São Paulo

Figura 2 - Faixas de Mitigação da Receita

Figura 3 - Tráfego esperado modelado 46

Figura 4 - Formas de Desconto de Fluxo de Caixa Equivalentes 47

Figura 5 - Tráfego real $x$ tráfego compensado 50

Figura 6 - Distribuição de Probabilidade do VPL - US\$ milhões

Figura 7 - VPL com faixas de mitigação por 10 anos e barreira de $20 \%$

Figura 8 - VPL com faixas de mitigação por 10 anos e barreira de $30 \%$

Figura 9 - VPL com faixas de mitigação por 20 anos e barreiras de $20 \%$

Figura 10 - VPL com faixas de mitigação por 20 anos e barreiras de $20 \%$ 


\section{Lista de tabelas}

Tabela 1 - Tipos de Opções $\quad 14$

$\begin{array}{lr}\text { Tabela } 2 \text { - Classificação das PPPs } & 18\end{array}$

Tabela 3 - Diferenças entre Opções Financeiras e Opções Reais $\quad 26$

Tabela 4 - Projeção de Passageiros por Trimestre 31

Tabela 5 - Cálculo do Fluxo de Caixa Livre 42

Tabela 6 - Comparativo de Receitas com e sem Contraprestação

Pecuniária x Número de Passageiros 43

Tabela 7 - Valores do PIB da Cidade de São Paulo 45

Tabela 8 - Resumo do Tráfego esperado 46

Tabela 9 - Mecanismo de mitigação de risco de tráfego 49

Tabela 10 - Valores (em US\$ MM) do mecanismo de mitigação de risco 56 